\title{
THE EDUCATIONAL STATUS OF PARENTS, AND INFANT AND CHILD MORTALITY IN RURAL NORTH INDIA
}

\author{
GEORGE B. SIMMONS and STAN BERNSTEIN \\ Center for Population Planning and Department for Health Planning and Administration, University \\ of Michigan, Ann Arbor, MI 48109, U.S.A.
}

Mortality among the very young is widely recognized as an important indicator of social well-being. Infant and child mortality is often lower among families with more educated parents, but the mechanisms underlying this relationship are poorly understood. The purpose of this paper is to explore the extent to which education can be considered a determinant of infant and child mortality in the context of a very poor community with very high mortality. In this community the prevailing levels of education are low, but infants and children in those families with relatively more education experience lower levels of mortality. These same families, in addition to their educational qualifications, share a number of other characteristics. Thus, the task of this paper is to disentangle the various forces which influence the probability of death for children and, where possible, to identify the independent role of education.

This paper is one of a series of explorations of the mortality and fertility experiences of a sample of couples from North India. This particular paper grows out of an increasing awareness that education may play a more important and certainly a more complex role in determining mortality than we realized when we initiated our earlier research on mortality in this region. Given the relatively low level of education in the region, we did not see strong theoretical or empirical reasons for expecting education to play a central role in determining neonatal mortality. In our work on the postneonatal period we used education as a measure of the family's access to resources. We did find in that research, however, that even a relatively gross measure of education had a strong effect on the mortality experience of female children in the post-neonatal period. It did not affect the mortality probability for male children. The differential effect is startling and unex-

This paper is based on data collected with support from the Government of India and USAID. An early stage of the analysis of the demographic data was supported with a grant from NICHD. We are grateful to our colleagues Celeste Smucker, Eric Jensen, B.D. Misra, Ali Ashraf, Prasanta Majumdar, and John Gross for help at various stages. 
pected. This paper represents a further exploration of the questions raised in that earlier research.

That there is a relationship between child mortality and education is widely accepted. (See Cochrane, 1980; Preston, 1980). There are several possible mechanisms through which education may affect mortality. The most frequently cited mechanism is that education may affect the basic characteristics of the individual parent in such a way as to enhance his or her ability to provide for the well-being of the children. In the strongest form of this hypothesis it is assumed that this transformation of the educated individual occurs independently of other factors in the environment. Education would have the same effect on a wealthy or a poor individual, etc. The most important alternative hypothesis is that education is a proxy for the general socioeconomic status of the individual and his or her family and it is not education per se but the whole complex of family characteristics which affect child survival. While under the first hypothesis we would expect education to havc an independent effect on child mortality, under the second, any effect would derive from a general process of social transformation and not from education alone.

Education is of course just one of the variables affecting mortality, and the nature of the other variables in the system may affect the way in which education works under either of the two hypotheses described above. If we think of mortality as primarily a biological process then the role of education may work largely through its influence on variables such as birth practices. Alternatively, if we think of mortality as an outcome of a resource allocation process then education may work by influencing the importance parents place on individual children, differentiated by parity and sex. The educational status of parents may also influence the way in which the health care system responds to a given family. Our purpose here will be, to the extent possible, to try to differentiate some of these mechanisms.

The analysis in this paper is based on interviews with a rural sample of husbands and wives living in 120 villages in Uttar Pradesh State in India. Information concerning fertility and mortality is based on the retrospective fertility histories collected in 1972. The wives were the major source of information for these histories but their information was checked wherever possible against similar information collected from husbands. The other variables used in the analysis reported here are based on or drawn from other parts of the same interviews. Details of the sampling and field procedures are not presented here but are available in other publications (Misra et al., 1981; Simmons et al., 1980; Smucker et al., 1980; Simmons et al., 1978).

The population discussed in this paper is heavily dependent upon agriculture, it is poor and it has little formal education. Per capita income at 
the time of the survey was less than $\$ 100$ per year and fifty-two percent of the husbands and eighty-seven percent of the wives had never been to school. Both fertility and mortality are high in this population. The crude birth rate is over 50 per thousand and the total fertility rate is 7.7 . We have estimated that infant mortality exceeded 200 per thousand during the reference period $1965-1969$. Indications are that it was considerably higher during the memory of the respondents.

IABLE I

Infant and Child Mortality Rates per Thousand Live Births for the 1965-1969 Birth Cohort by Sex and Age at Death

\begin{tabular}{llll}
\hline Sex & Age at death & & \\
\cline { 2 - 4 } & $\begin{array}{l}\text { Within first } \\
\text { month }\end{array}$ & $\begin{array}{l}\text { One month- } \\
\text { eleven months }\end{array}$ & $\begin{array}{l}\text { One year }- \\
\text { two years, } \\
\text { eleven months }\end{array}$ \\
\hline Female & 94.30 & 79.24 & 88.41 \\
Male & 104.84 & 56.41 & 60.97 \\
Total & 100.40 & 67.34 & 74.07 \\
\hline
\end{tabular}

Some basic information concerning mortality is summarized in Table I. The overall level of infant mortality in the uncorrected data is on the order of 170 per thousand births. For the second and third years of life the mortality rate is 74 per thousand children surviving the first year. The first year can be broken into two parts. During the first month there are about 100 deaths per thousand live births. During the rest of the first year of life the rate is 67 per thousand. Thus for this population most of the infant mortality takes place during the first month of life. Another interesting characteristic of this data is that mortality rates of male and female births are much more similar during the first month than they are during the later periods.

Further insight into the characteristics of mortality in this region can be gained by examining Table II which shows mortality rates by sex, age, and respondent-reported cause. It should be stressed here that the causes are derived from the reports of the village respondents and would not be expected to correspond very closely to cause of death reports by trained medical practitioners. Discussion with physicians and persons with local experience leads us to conclude that tetanus deaths may be more accurately reported than other causes in the list, but considerable misreporting is probably associated with all categories. Keeping these reservations in mind, it is noteworthy how strongly the reports of tetanus are confined to the first period, how similar are the reported levels of tetanus-induced deaths 
TABLE II

Infant and Child Mortality Rates per 100,000 Live Births by Sex, Age at Death and Cause of Death for the 1965-1969 Birth Cohort

Rates by cause of death

\begin{tabular}{|c|c|c|c|c|c|c|c|c|c|c|}
\hline 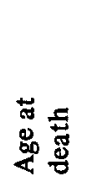 & ॐ & 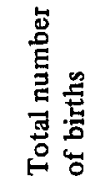 & 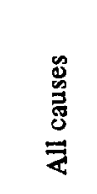 & 疋 & 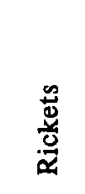 & 总莺 & 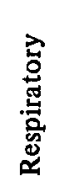 & 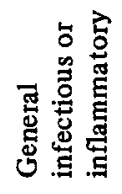 & $\stackrel{5}{5}$ & $\underset{z}{z}$ \\
\hline 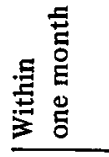 & $\begin{array}{l}\text { ALL } \\
\text { M } \\
\text { F }\end{array}$ & $\begin{array}{l}3267 \\
1755 \\
1527\end{array}$ & $\begin{array}{r}10040 \\
10484 \\
9430\end{array}$ & $\begin{array}{l}5356 \\
5472 \\
5173\end{array}$ & $\begin{array}{r}184 \\
57 \\
327\end{array}$ & $\begin{array}{l}398 \\
342 \\
458\end{array}$ & $\begin{array}{l}398 \\
570 \\
196\end{array}$ & $\begin{array}{l}459 \\
570 \\
327\end{array}$ & $\begin{array}{l}1286 \\
1368 \\
1179\end{array}$ & $\begin{array}{l}1959 \\
2108 \\
1768\end{array}$ \\
\hline 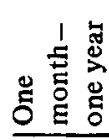 & $\begin{array}{l}\text { ALL } \\
M \\
F\end{array}$ & $\begin{array}{l}3267 \\
1755 \\
1527\end{array}$ & $\begin{array}{l}6734 \\
5641 \\
7924\end{array}$ & $\begin{array}{l}520 \\
455 \\
589\end{array}$ & $\begin{array}{r}949 \\
684 \\
1244\end{array}$ & $\begin{array}{l}612 \\
627 \\
589\end{array}$ & $\begin{array}{l}888 \\
912 \\
851\end{array}$ & $\begin{array}{l}1837 \\
1197 \\
2554\end{array}$ & $\begin{array}{l}673 \\
513 \\
851\end{array}$ & $\begin{array}{l}1255 \\
1254 \\
1244\end{array}$ \\
\hline 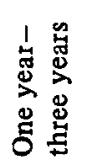 & $\begin{array}{l}\text { ALL } \\
\text { M } \\
\text { F }\end{array}$ & $\begin{array}{l}3267 \\
1755 \\
1527\end{array}$ & $\begin{array}{l}7407 \\
6097 \\
8841\end{array}$ & $\begin{array}{r}92 \\
114 \\
65\end{array}$ & $\begin{array}{l}1683 \\
1481 \\
1899\end{array}$ & $\begin{array}{l}612 \\
456 \\
786\end{array}$ & $\begin{array}{l}918 \\
855 \\
982\end{array}$ & $\begin{array}{l}2356 \\
1880 \\
2881\end{array}$ & $\begin{array}{r}765 \\
570 \\
1048\end{array}$ & $\begin{array}{r}977 \\
741 \\
1244\end{array}$ \\
\hline
\end{tabular}

of male and female infants, and how different are the general patterns of cause of death for male and female children in the post-neonatal periods.

The observations drawn from the first two tables have led us to the conclusion that any analysis of the cause of death in this region will be mistaken if it does not differentiate the first month from the later periods, and furthermore if it does not differentiate between tetanus- and nontetanus-caused risks in the neonatal period and between male and female deaths in the later periods. Thus, in our view it is misleading to treat mortality as a homogeneous risk for all children. If one wants to understand mortality and possible interventions that might be used to affect mortality it is necessary to break up the data into its constituent units.

We have already indicated that the general level of education in the sample population is low. Several possible measures of education could be used for the present analysis. We can examine the educational status of the husband, of the wife, or of both. We can measure education by the number of years of schooling or use broad categories. For most of the analyses in this paper we have placed emphasis on the husband because a much larger proportion of husbands than wives have had at least some schooling. We have supplemented this in some analyses with an index of education which takes into account the educational status of both husband and wife. In general, we 
have used a categorical variable that combines people into three groups.

It should be emphasized that the education offered by village schools in Uttar Pradesh is limited. For most of the respondents, education was confined to less than eight years and emphasized basic reading and writing and some arithmetic, supplemented by a very modest exposure to Indian history and literature. Those with some high school may have a somewhat wider training and thus have for some analyses been treated as a separate category, but they are few and do not in any case receive a very thorough education. For example, it is unlikely that they would be systematically exposed to training in the area of health. Thus, the nature of the sample is such that we can say little about how an educational system that reached a higher proportion of the population or that was more effective in its instructional programs would affect health.

Table III illustrates the relationship between education and mortality by the basic age categories used in the later analyses. Three alternative measures of education are presented in the tables. The first two measure the educational status of the father and differ in the way they define the highest education category. The first index defined high education as more than six years of school. The second defined the highest category as at least some exposure to high school. The obvious problem with the latter classification is that a very small proportion of the sample has had any exposure to high school. The third panel uses a measure of education that defined a separate category for those households where the mother has had some education.

There are considerable differences in the mortality experience of children according to the educational attainment of their parents. In general, the mortality differentials between those with no education and those with a moderate amount of education are small, but for all three measures of education, children with the most educated parents experience substantially lower levels of mortality. For the education measure used in Panel A of Table III, there is little indication of differentials during the neonatal period, but the child mortality rate for the post-neonatal period is one third lower for the most educated group than it is for the rest of the sample. The same basic result is shown in panel $\mathrm{B}$ of the table, which used a more extreme cut-off point for husband's education. Moreover, for this measure of education there is a strong differential for both the neonatal and the post-neonatal periods. Mortality is distinctly lower for both age periods among those with some high school education.

The measure of education which differentiates households where the mother has some education presents a third variation of the picture. In this case the differentials in the neonatal period are larger than for the other education measures, but the differentials in the post-neonatal period are 


\section{TABLE III}

Mortality per Thousand Live Births by Risk Category and Education of Parents

\begin{tabular}{|c|c|c|c|c|c|c|}
\hline & \multicolumn{3}{|c|}{ A. Father's education } & \multirow[t]{2}{*}{ At risk } & \multirow[t]{2}{*}{ Deaths } & \multirow[t]{2}{*}{ \% Died } \\
\hline & No ed. & Primary & Some sec. & & & \\
\hline \% Samplc births & 53.60 & 27.40 & 19.00 & & & \\
\hline \multicolumn{7}{|l|}{ Risk category } \\
\hline Neonatal tetanus & 5.27 & 4.93 & 5.39 & 2744 & 142 & 5.17 \\
\hline Neonatal non-tet & 2.87 & 2.27 & 3.28 & 2744 & 76 & 2.77 \\
\hline Neonatal unknown & 2.19 & 2.27 & 0.96 & 2744 & 54 & 1.97 \\
\hline Total neonatal & 10.33 & 9.47 & 9.63 & 2744 & 272 & 9.91 \\
\hline Month 2-11 deaths & 12.36 & 12.08 & 7.89 & 2472 & 283 & 11.45 \\
\hline Total IMR & 21.41 & 20.40 & 16.76 & 2744 & 555 & 20.23 \\
\hline Year 2 and 3 deaths & 7.66 & 6.87 & 3.94 & 2744 & 147 & 6.72 \\
\hline Total post-neonatal & 19.07 & 18.11 & 11.51 & 2472 & 430 & 17.39 \\
\hline \multirow[t]{3}{*}{ Total child deaths } & 27.43 & 25.87 & 20.04 & 2744 & 702 & 25.58 \\
\hline & \multicolumn{3}{|c|}{ B. Father's education } & At risk & Deaths & $\%$ Died \\
\hline & No ed. & To HS & HS PL & & & \\
\hline$\%$ Sample births & 53.60 & 39.80 & 6.60 & & & \\
\hline \multicolumn{7}{|l|}{ Risk category } \\
\hline Neonatal tetanus & 5.27 & 5.43 & 3.31 & 2744 & 142 & 5.17 \\
\hline Neonatal non-tet & 2.87 & 2.58 & 3.31 & 2744 & 76 & 2.77 \\
\hline Neonatal unknown & 2.19 & 1.93 & 0.55 & 2744 & 54 & 1.97 \\
\hline Total neonatal & 10.33 & 9.94 & 7.18 & 2744 & 272 & 9.91 \\
\hline Month 2-11 deaths & 12.36 & 11.35 & 4.76 & 2472 & 283 & 11.45 \\
\hline Total IMR & 21.41 & 20.17 & 11.60 & 2744 & 555 & 20.23 \\
\hline Year 2 and 3 deaths & 7.66 & 6.69 & 0.00 & 2744 & 147 & 6.72 \\
\hline Total post-neonatal & 19.07 & 17.28 & 4.76 & 2472 & 430 & 17.39 \\
\hline \multirow[t]{3}{*}{ Total child deaths } & 27.43 & 25.51 & 11.60 & 2744 & 702 & 25.58 \\
\hline & \multicolumn{3}{|c|}{ C. Combined education } & At risk & Deaths & $\%$ Died \\
\hline & Both no & Father only & Mother & & & \\
\hline$\%$ Sample births & 52.10 & 37.80 & 10.20 & & & \\
\hline \multicolumn{7}{|l|}{ Risk category } \\
\hline Neonatal tetanus & 5.24 & 5.66 & 3.62 & 2744 & 142 & 5.17 \\
\hline Neonatal non-tet & 2.90 & 2.93 & 1.45 & 2744 & 76 & 2.77 \\
\hline Neonatal unknown & 2.12 & 2.15 & 0.72 & 2744 & 54 & 1.97 \\
\hline Total neonatal & 10.27 & 10.73 & 5.80 & 2744 & 272 & 9.91 \\
\hline $\begin{array}{l}\text { Month } 2-11 \text { deaths } \\
\text { Total IMR }\end{array}$ & $\begin{array}{l}12.47 \\
21.46\end{array}$ & $\begin{array}{l}11.26 \\
20.78\end{array}$ & $\begin{array}{r}6.92 \\
12.32\end{array}$ & $\begin{array}{l}2472 \\
2744\end{array}$ & $\begin{array}{l}283 \\
555\end{array}$ & $\begin{array}{l}11.45 \\
20.23\end{array}$ \\
\hline Year 2 and 3 deaths & 7.84 & 6.40 & 2.48 & 2744 & 147 & 6.72 \\
\hline Total post-neonatal & 19.34 & 16.94 & 9.23 & 2472 & 430 & 17.39 \\
\hline Total child deaths & 27.62 & 25.85 & 14.49 & 2744 & 702 & 25.58 \\
\hline
\end{tabular}


TABLE IV

Mortality by Sex per Thousand Live Births by Risk Category and Education of Parents

\begin{tabular}{|c|c|c|c|c|c|c|}
\hline & \multicolumn{2}{|c|}{ Both no } & \multicolumn{2}{|c|}{ Father only } & \multicolumn{2}{|c|}{ Mother also } \\
\hline & Male & Female & Male & Female & Male & Female \\
\hline$\%$ In sample & 53.00 & & 36.70 & & 10.30 & \\
\hline \% In sample & & 51.00 & & 39.00 & & 10.00 \\
\hline \multicolumn{7}{|l|}{ Risk category } \\
\hline Neonatal tetanus & 5.39 & 5.07 & 5.69 & 5.62 & 4.73 & 2.34 \\
\hline Neonatal non-tet & 3.29 & 2.46 & 3.04 & 2.81 & 1.35 & 1.56 \\
\hline Neonatal unknown & 2.63 & 1.54 & 2.09 & 2.21 & 0.00 & 1.56 \\
\hline Total neonatal & 11.32 & 9.06 & 10.82 & 10.64 & 6.08 & 5.47 \\
\hline Year one deaths & 9.94 & 15.37 & 9.57 & 13.03 & 8.63 & 4.96 \\
\hline Total IMR & 20.13 & 23.04 & 19.35 & 22.29 & 14.19 & 10.16 \\
\hline Year 2 and 3 deaths & 7.08 & 8.78 & 5.18 & 7.75 & 1.57 & 3.48 \\
\hline Tutal post-neonatal & 16.32 & 22.80 & 14.26 & 19.78 & 10.07 & 8.26 \\
\hline Total child deaths & 25.79 & 29.80 & 23.53 & 28.31 & 15.54 & 13.28 \\
\hline
\end{tabular}

somewhat smaller than for the measure of education which distinguishes husbands with some high school education.

Table IV shows the way that mortality rates vary by the sex of the birth for the combined education measure. The key result here is that those households where the mother has had some education tend to have lower female than male mortality rates. That is, children of both sexes born into those households experience lower levels of mortality than do children born into households where neither parent or only the father is educated, but female children do particularly well.

The tables discussed above demonstrate a clear measure of association between education and mortality, but they do not yield any definitive understanding of the causal mechanisms that are involved. Is the measure of education just an indication of high social status? If so, it may be social or economic status (or a lack thereof) which explains why mortality is higher in some groups than in others. What are the other factors which influence the level of mortality and how do they relate to education?

A preliminary indication that education is associated with social and economic status is given in Table $\mathrm{V}$, which shows the relationship between education and the amount of land owned by the family. The more land owned by the family, the more likely is the husband to have some education. For the families that own no land, only thirty-five percent of the husbands have any education: for those families in the highest land owning category, over seventy percent have some education. Nearly three times as many mothers from the largest landholding families than from the landless 
TABLE V

The Relationship Between Education of the Parents and Landholding, $N=2733$

\begin{tabular}{|c|c|c|c|c|}
\hline & \multicolumn{3}{|c|}{ Education } \\
\hline \multicolumn{2}{|c|}{ Landholding } & None & Husband only & Wife some \\
\hline \multicolumn{2}{|c|}{ None 1} & \multirow{2}{*}{$\begin{array}{l}65.1 \\
61.2\end{array}$} & 22.0 & 12.8 \\
\hline \multirow[t]{3}{*}{ Least } & \multirow{3}{*}{$\begin{array}{l}2 \\
3 \\
4\end{array}$} & & 26.3 & 12.5 \\
\hline & & 58.0 & 26.6 & 15.4 \\
\hline & & 39.5 & 31.9 & $\begin{array}{l}15.4 \\
28.6\end{array}$ \\
\hline Most & 5 & 28.8 & 33.3 & 37.9 \\
\hline
\end{tabular}

families have some education. The same general pattern holds for other measures of education and for other measures of social or economic status such as caste or income. There is also a statistically significant tendency for younger parents to have more education.

The measures of association between education and mortality reported above are suggestive, but they leave many questions unresolved. To examine further the role of education as a determinant of mortality, the next two sections examine separately the multivariate correlates of mortality in the neonatal and in the post-neonatal period. In each case the determinants of death are examined in the context of a complex model of behavior. The details of these models are reported in the papers mentioned earlier.

The general analytic technique used is multiple regression where the dependent variable in the analysis is the log odds of death during the defined period. This form of the dependent variable is appropriate for a dichotomous variable such as mortality.

In the analyses that follow, we (with some minor changes designed to focus on education) restrict our attention to those variables which we hypothesized in our earlier research to influence mortality most directly. The key variables in the neonatal period center around the environmental factors which might increase the probability of tetanus or genetic birth defects. Thus, both the tetanus and the non-tetanus models include variables related to the village health environment, the type of birth attendant, and time to the nearest health center. In addition, the tetanus model includes variables indicating the ownership of large animals, and the existence of previous child deaths due to tetanus. The non-tetanus model includes the age of the mother. Certain variables that might have been included if we had direct measures were left out because information was lacking - the birth weight of the child, the nutritional status of the mother, and the birth practices used during the delivery are the most important of these.

For the post-neonatal period we have hypothesized that the most important influences were those elements in the environment that might affect 
the probability of infectious disease and those that relate to parental decisions concerning the level of investment in an individual child. Because the earlier research summarized in Tables I and II had indicated such a strong difference during the post-neonatal period in the probability of death for male and female children, separate analyses were done for males and females. For each regression explanatory variables included: the village health environment and the time to the nearest hospital as measures of the health environment and education; the existence of persons in the family to support the childrearing efforts of the parents (e.g., older children or inlaws who can help with child care); the existence of older male or female children in the family to compete with the reference birth; the parity of the mother; and a measure of the mother's preference for additional children by sex.

For this paper we have re-estimated the neonatal regressions to include the education and preference variables to assure comparability in the results for the two time periods. We have also re-estimated the neonatal regressions by sex so that sex-specific projections of the effects of education can be made for the entire three-year period of risk.

\section{The Determinants of Mortality During the First Month}

In this section we discuss our empirical research findings related to the first month of life. Separate logit regressions are estimated by sex for tetanus and non-tetanus caused deaths. Thus four regressions are estimated in sum. The strategy of estimating four equations has the disadvantage of reducing the number of cases examined in each regression, but it permits greater comparability with the post-neonatal results [1].

Statistics for the male and female neonatal tetanus mortality regressions are given in Table VI. Equivalent results for the male and female non-tetanus neonatal model are shown in Table VII. Each table is divided into two panels, one for the regression relating to male infants and the other for females. Each panel is further subdivided into four subsections. The first three sections contain the statistical results for the three major categories of independent variables: health environment, family environment and additional children desired. The last section provides the regression statistics. For the continuous variables in the health environment section and for each category of the other variables three statistics are provided. The first is the number of observations corresponding to the category of the independent variable, the second is the regression coefficient and the third is the pseudo $t$-statistic (the ratio of the regression coefficient to its standard error). Additionally for each categorical variable a chi-square statistic is presented to test the significance of the variable taken as a whole. 


\section{TABLE VI}

Neonatal Tetanus Mortality: Dichotomous Regressions

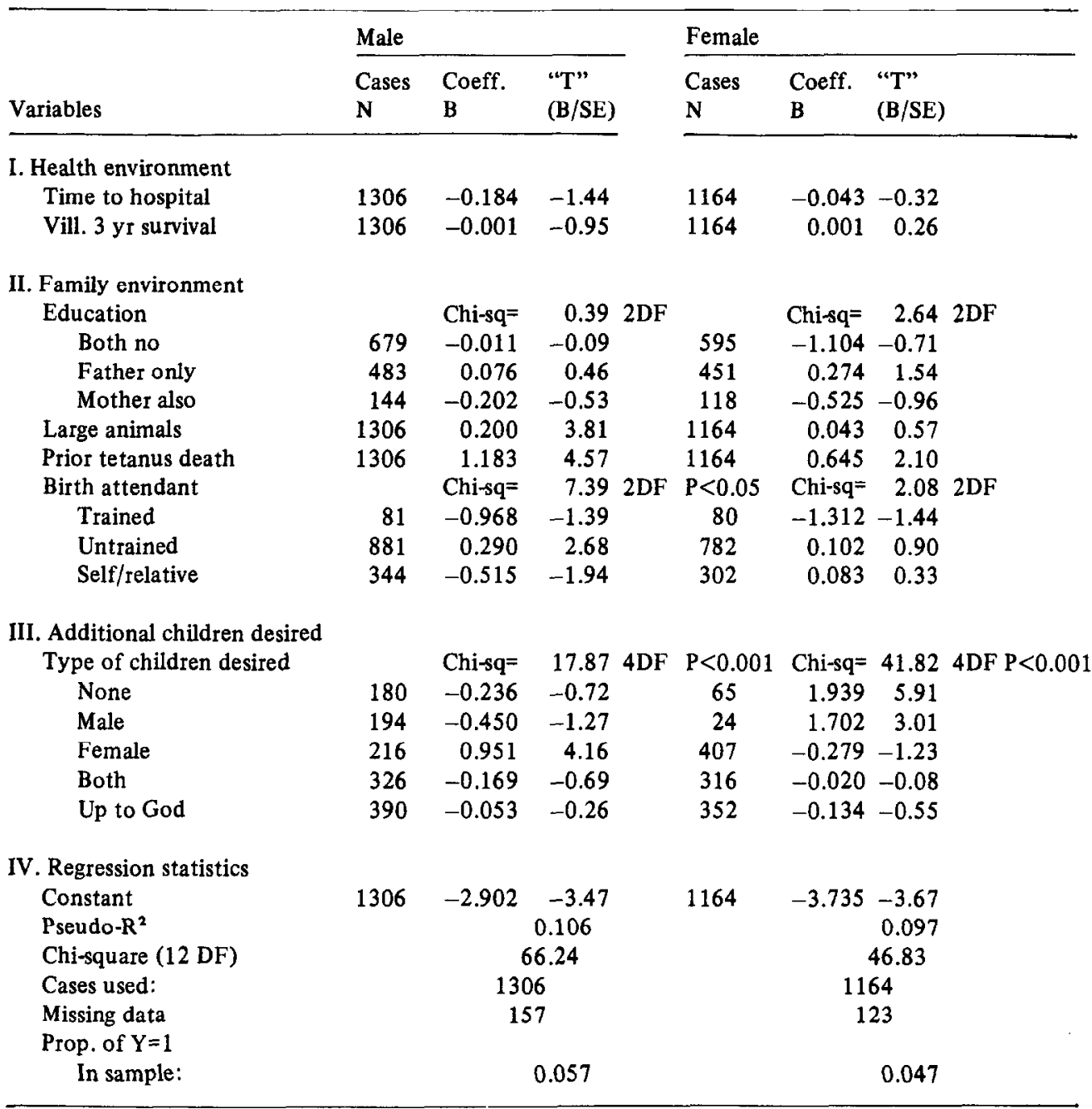

For each regression, the bottom panel of the table provides some summary statistics including the statistics relating to the constant terms in the regression, the number of observations used in the regression, the pseudo- $\mathrm{R}^{2}$ (the percentage of the reduction of predictive error accounted for by the regression), the number of cases eliminated due to missing data, and the proportion of the sample dying during the period of observation.

The regressions for tetanus deaths are summarized in Table VI. Both male and female regressions are significant, but more variation is explained in the male regression. 
TABLE VII

Neonatal Non-Tetanus Mortality: Dichotomous Regressions

\begin{tabular}{|c|c|c|c|c|c|c|}
\hline \multirow[b]{3}{*}{ Variables } & \multicolumn{3}{|l|}{ Male } & \multicolumn{3}{|l|}{ Female } \\
\hline & Cases & Coeff. & "T" & Cases & Coeff. & "T" \\
\hline & $\mathbf{N}$ & B & (B/SE) & $\mathrm{N}$ & B & $(\mathrm{B} / \mathrm{SE})$ \\
\hline \multicolumn{7}{|l|}{ I. Health environment } \\
\hline Time to hospital & 1292 & 0.266 & 1.86 & 1145 & 0.119 & 0.73 \\
\hline Vill. 3 yr survival & 1292 & -0.002 & -0.98 & 1145 & -0.004 & -2.68 \\
\hline \multicolumn{7}{|l|}{ II. Family environment } \\
\hline Education & & Chi-sq $=$ & $1.572 \mathrm{DF}$ & & Chi-sq $=$ & $=1.092 \mathrm{DF}$ \\
\hline Both no & 669 & 0.081 & 0.47 & 586 & 0.005 & 0.03 \\
\hline Father only & 479 & 0.133 & 0.61 & 443 & 0.161 & 0.69 \\
\hline Mother also & 144 & -0.821 & -1.24 & 116 & -0.640 & -0.94 \\
\hline Landholding & & Chi-sq $=$ & $3.814 \mathrm{DF}$ & & Chi-sq $=$ & $=1.794 \mathrm{DF}$ \\
\hline None & 241 & -0.456 & -1.18 & 194 & -0.138 & -0.32 \\
\hline $0-4.9$ & 364 & 0.356 & 1.44 & 311 & -0.310 & -0.91 \\
\hline $5.0-9.9$ & 291 & -0.218 & -0.65 & 279 & 0.241 & 0.79 \\
\hline $10.0-19.9$ & 285 & 0.267 & 0.92 & 258 & 0.286 & 0.89 \\
\hline $20.0+$ & 111 & -0.292 & -0.43 & 103 & -0.173 & -0.25 \\
\hline Mother's age & & Chi-sq $=$ & $5.594 \mathrm{DF}$ & & Chi-sq $=$ & $=10.604 \mathrm{DF} P<0.05$ \\
\hline $15-19$ & 188 & 0.767 & 2.27 & 175 & 1.156 & 3.14 \\
\hline $20-24$ & 370 & 0.110 & 0.42 & 300 & -0.148 & -0.41 \\
\hline $25-29$ & 353 & -0.138 & -0.48 & 286 & -0.115 & -0.31 \\
\hline $30-34$ & 241 & -0.396 & -0.97 & 242 & 0.255 & 0.72 \\
\hline $35+$ & 140 & -0.290 & -0.58 & 142 & -1.313 & -0.47 \\
\hline Birth attendant & & Chi-sq= & $4.452 \mathrm{DF}$ & & Chi-sq $=$ & $=0.181 \mathrm{DF} * *$ \\
\hline Trained & 79 & 0.355 & 0.60 & & $* *$ & \\
\hline Untrained & 870 & -0.229 & -2.09 & 765 & -0.055 & -0.42 \\
\hline Self/relative & 343 & 0.500 & 1.98 & 380 & 0.110 & 0.42 \\
\hline \multicolumn{7}{|l|}{ III. Additional children desired } \\
\hline Type of children desired & & Chi-sq $=$ & $5.974 \mathrm{DF}$ & & Chi-sq= & $=1.494 \mathrm{DF}$ \\
\hline None & 175 & 0.100 & 0.20 & 64 & -0.769 & -0.77 \\
\hline Male & 191 & -1.459 & -1.75 & 23 & 0.502 & 0.48 \\
\hline Female & 215 & 0.201 & 0.53 & 400 & 0.029 & 0.11 \\
\hline Both & 325 & -0.039 & -0.12 & 311 & -0.173 & -0.53 \\
\hline Up to God & 386 & 0.597 & 2.31 & 347 & 0.231 & 0.84 \\
\hline \multicolumn{7}{|l|}{ IV. Regression statistics } \\
\hline Constant & 1292 & -3.0455 & -2.71 & 1145 & -0.787 & $7-0.67$ \\
\hline Pseudo- $\mathrm{R}^{2}$ & & & 073 & & & 0.074 \\
\hline Chi-square $(18 \mathrm{DF})^{* *}$ & & 28. & & & & 3.03 \\
\hline Cases used: & & 1292 & & & 1145 & \\
\hline Missing data & & 165 & & & 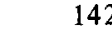 & \\
\hline \multicolumn{7}{|l|}{ Prop. of $Y=1$} \\
\hline In sample: & & & 032 & & & 28 \\
\hline
\end{tabular}


The explanatory variables which are important differ in the two cases. In these regressions the village three-year survival rate is not significant. The probability of tetanus deaths is not greater for children born in villages with high mortality. Among the family environment variables, the statistically significant variables are the number of large animals in the house, the existence of prior tetanus deaths within the family and the kind of birth attendant at the last birth. All of these variables are plausibly linked with the probability of exposure to tetanus. They may also measure the socioeconomic status of the family to some degree. Education is not significantly related to the probability of tetanus deaths.

The family size preference variable is a strong predictor of mortality, particularly for females. A similar result will be reported for the postneonatal deaths, and detailed discussion is reserved for that section. Here it only need be pointed out that there are several alternative explanations for this finding, some relating to the definition of the variables used here and some relating to the substantive relationships involved.

Table VII reports the results of regressions for non-tetanus-caused deaths during the first month. These regressions are not as statistically significant as those for tetanus-related deaths.

That variance which is explained tends to be explained by variables that describe the general health environment of a child. Thus the village threeyear survival rate is negatively associated with mortality for female births and the time to the hospital is marginally positively associated with the mortality of males. None of the other variables approach conventional levels of statistical significance. In particular, education is not significantly related to the non-tetanus neonatal mortality in the sample.

To summarize the results for the neonatal period, while the regressions show a reasonably high degree of explanation of mortality during the first month, education is not a significant explanatory variable in any of the regressions. When the role of education is examined in the presence of controls for socioeconomic status or age, the role of education is not significant. While children born in families where the mother has some education have in all cases a somcwhat lower probability of death, the differential advantage is small.

\section{Determinants of Mortality in the Post-Neonatal Period}

In our research on mortality during the post-neonatal period we have hypothesized that there are two general kinds of variables which affect the probability of mortality. The first set relates to the health environment of the family and is measured by the village three-year survival rate and the 
TABLF: VIII

Post-Neonatal Mortality: Dichotomous Regressions

\begin{tabular}{|c|c|c|c|c|c|c|c|c|c|}
\hline \multirow[b]{2}{*}{ Variables } & \multicolumn{4}{|l|}{ Male } & \multicolumn{5}{|c|}{ Iemale } \\
\hline & $\begin{array}{l}\text { Cases } \\
\mathrm{N}\end{array}$ & $\begin{array}{l}\text { Coeff. } \\
\text { B }\end{array}$ & $\begin{array}{l}\text { "T" } \\
\text { (B/SE) }\end{array}$ & & $\begin{array}{l}\text { Cases } \\
\mathrm{N}\end{array}$ & $\begin{array}{l}\text { Coeff. } \\
\text { B }\end{array}$ & $\begin{array}{l}\text { "T" } \\
\text { (B/SE) }\end{array}$ & & \\
\hline \multicolumn{10}{|l|}{ I. Health environment } \\
\hline Time to hospital & 1247 & -0.120 & 1.46 & & 1131 & -0.108 & -1.37 & & \\
\hline Vill. 3 y r survival & 1247 & -0.002 & -2.87 & & 1131 & -0.001 & -0.73 & & \\
\hline \multicolumn{10}{|l|}{ Il. Iamily environment } \\
\hline lducation & & Chi-sq= & $2.802 \mathrm{DI}$ & & & Chi-sq= & 13.56 & $2 \mathrm{DF}$ & $\mathrm{P}<0.001$ \\
\hline Both no & 653 & 0.074 & 0.91 & & 579 & 0.259 & 3.05 & & \\
\hline Father only & 457 & 0.028 & 0.62 & & 435 & -0.053 & -0.49 & & \\
\hline Mother also & 137 & -0.448 & -1.66 & & 117 & 1.085 & 3.24 & & \\
\hline Family support & & Chi-sq $=$ & $12.162 \mathrm{DF}$ & $\mathrm{P}<0.001$ & & Chi-sq $=$ & 14.11 & 2DF & $\mathrm{P}<0.001$ \\
\hline None & 223 & 0.626 & 3.08 & & 197 & 0.760 & 3.70 & & \\
\hline Some & 791 & 0.042 & 0.62 & & 697 & 0.155 & -2.29 & & \\
\hline Much & 233 & -0.741 & 3.38 & & 237 & 0.175 & -0.91 & & \\
\hline Older male competitor & & Chi-sq= & $0.69 \mathrm{lDl}:$ & & & Chi-sq= & 3.36 & IDF: & $\mathrm{P}<0.10$ \\
\hline None & 935 & 0.043 & 0.83 & & 813 & -0.103 & -1.83 & & \\
\hline One plus & 312 & -0.127 & 0.83 & & 318 & 0.264 & 1.83 & & \\
\hline Older female competitor & & Chi-sq $=$ & $0.26 \quad 1 \mathrm{Dl}$ & & & Chi-sq= & 0.13 & 1DI: & \\
\hline None & 931 & 0.026 & 0.51 & & 847 & 0.020 & 0.36 & & \\
\hline One plus & 316 & -0.077 & 0.51 & & 284 & -0.059 & -0.36 & & \\
\hline Parity & & Chi-sq $=$ & $8.083 \mathrm{Dl}:$ & $P<0.05$ & & Chi-sq= & 2.54 & $3 \mathrm{DI}$ & \\
\hline \#1 & 151 & 0.813 & -2.66 & & 141 & 0.051 & 0.19 & & \\
\hline$\# 2-\# 3$ & 335 & 0.024 & -0.17 & & 296 & 0.230 & 1.54 & & \\
\hline$\# 4-\# 6$ & 450 & 0.230 & 2.01 & & 389 & -0.133 & 1.06 & & \\
\hline \#7 plus & 311 & 0.087 & 0.51 & & 305 & 0.078 & .0 .48 & & \\
\hline \multicolumn{10}{|l|}{ III. Additional children desired } \\
\hline Type of children desired & & Chi-sq= & $21.684 \mathrm{DI}:$ & $\mathrm{P}<0.001$ & & Chisq $=$ & 122.71 & $4 \mathrm{DI}$ & $\mathbf{P}<0.001$ \\
\hline None & 172 & 0.331 & 1.62 & & 56 & 3.011 & 9.10 & & \\
\hline Male & 196 & -0.454 & 2.05 & & 21 & 2.785 & 5.57 & & \\
\hline Female & 195 & 0.680 & 4.06 & & 401 & -0.365 & -2.96 & & \\
\hline Both & 313 & 0.299 & -1.85 & & 311 & 0.586 & -3.64 & & \\
\hline Up to God & 371 & -0.019 & -0.15 & & 342 & 0.297 & 2.46 & & \\
\hline \multicolumn{10}{|l|}{ IV. Regression statistics } \\
\hline Constant & 1247 & -0.176 & -0.32 & & 1131 & -1.049 & -1.81 & & \\
\hline Pseudo-R ${ }^{2}$ & \multicolumn{4}{|c|}{0.044} & \multicolumn{5}{|c|}{0.127} \\
\hline Chi-square (15 DF) & \multicolumn{4}{|c|}{$57.24 \mathrm{P}<0.001$} & \multicolumn{5}{|c|}{$180.15 \quad P<0.0001$} \\
\hline \# Cases used: & \multicolumn{4}{|c|}{1247} & \multicolumn{5}{|c|}{1131} \\
\hline \# Missing data & \multicolumn{4}{|c|}{210} & \multicolumn{5}{|c|}{156} \\
\hline \multicolumn{10}{|l|}{ Prop. of $Y=1$} \\
\hline In sample: & \multicolumn{4}{|c|}{0.148} & \multicolumn{5}{|c|}{0.201} \\
\hline
\end{tabular}

accessibility of medical care. The second set relates to the amount of resources the family wants to or is able to invest in the child and its environment. We have no direct measure of these variables, but they can be indirectly indicated by a subset of variables relating to the family environment and a further subset relating to the family's desires about additional children. 
The regressions for male and female post-neonatal mortality are presented in Table VIII. There are a number of features of these results that bear careful examination, but a salient feature is that the reduction of predictive error is approximately two-and-a-half times greater in the female regressions than in the male regressions. Both regressions, on the other hand, have a significant degree of explanatory power and are comparatively robust given the estimation techniques that are employed.

Among the environmental variables, in neither of these regressions nor in any of the supporting regressions that were run was the time required to reach the primary health center a significant determinant of mortality. On the other hand, the healthiness of children residing in the village of the respondent is significantly associated with mortality in the male regressions. Male infants born into a relatively healthy environment are much more likely to survive than those born into villages with low levels of survival.

Among the variables related to the family's investment in their children, the results are somewhat more complicated. First, there is the education of the parents. Under either of the hypotheses discussed earlier, the more educated the family, the more we would expect them to have the knowledge and the ability to draw on outside sources of support in maintaining the health of the children in the family. This notion is confirmed for the female children but not for males. Female children are significantly more likely to survive among the relatively educated portion of the sample than among the uneducated. Supporting regressions suggest that this effect is particularly important during the first year and less so during the second and third years of life. The differential effect of education by sex of child may also indicate that educated parents are less likely to direct resources away from relatively less wanted female children. This interpretation will be further discussed in the next section.

The second measure of resources is the degree of family support available to the mother of the child. Mothers who live in nuclear families without older children to help in the care of infants and toddlers are likely to have more difficulty in bringing their children through crises than mothers who have a number of older children or who live in a large joint-family environment. The general notion of the importance of a supportive environment is confirmed for both male and female infants. In both cases children born into situations where there is no additional support in the environment are more likely to die than others. In contrast, the existence of older children who are competitive with a reference birth may be expected to reduce the survival probabilities of infants. Thus, we have introduced variables measuring whether there is an older male or female competitor (i.e., a child born within three years of the reference child and surviving into the reference period). Older competitors do not affect the survival chances in the neonatal 
period with the exception of the case where a female infant is born into a family with an older male competitor, in which case the survival probability for the female child in question is reduced. Thus there is some possibility that families may be giving preference to the existing young male children rather than to newborn females.

The results described in the paragraph above are all closely related to parity. The competitor result, for example, might be thought to be determined by the fact that first births will be definition have no older competitor and are known to have somewhat higher mortality than other births, according to most research studies. To control for this possibility and for the possibility that the parity may also influence variables such as family support or, through a cohort effect, the educational environment, we have introduced parity into the regressions. Parity also serves as an independent biological control since it is often hypothesized that there is an important underlying $\mathrm{J}$-shaped relationship between mortality and parity. Parity turns out to be significant for males and insignificant for females in these regressions and was insignificant in most of the supporting regressions. This result strengthens the results reported above which measure important determinants of mortality. The differential pattern for male and female births again raises questions similar to the case of the education variable as to whether the impact of parity is affected by family composition preferences.

The remaining variable relates to the additional children desired $[2]$. First, it should be noted that the impact of this preference variable is much stronger for females than it is for males. Those female children born to families who desire additional female children are much more likely to survive, and those born to families who desire no additional children of either sex or desire only male children are more likely to die. Male children are much less subject to this kind of preference, though death is more likely for them when only females are desired and less likely when only males are desired. For both males and females the regression coefficients tend to be significant and patterned as hypothesized. It seems fair to conclude from this evidence and from the competitor result that female children are systematically disadvantaged and that the choices are rational and deliberate in the usually accepted senses of these terms.

To summarize, in the multivariate context the influence of education in the post-neonatal period is restricted to female births. Those girls born to households where the mother has received some education are significantly less likely to die than are their counterparts born to families where neither parent is educated or just the father has attended school. This effect is relatively strong, overshadowed only by the effect of the preference variable. 


\section{The Role of Education as a Determinant of Mortality During the First} Three Years

In Table III we showed that mortality was significantly lower for the most educated groups than it was for their fellow villagers who had little or no education. In the previous sections of this paper we have discussed the determinants of mortality for different age and sex groups. When analyzed in this fashion the only age/sex groups for which education is a significant predictor is the female post-neonatal group.

Education may, in general, act as a proxy for social status or age to the extent that it is related to neonatal mortality in estimations like those of Table III. When estimations of neonatal mortality are made with education as just one of the explanatory variables, education is no longer statistically significant. In the post-neonatal period the role of education is more complex. Not only is its effect on post-neonatal mortality important, but when we ran a separate regression adding the landholding of the family as a proxy, the effect remained strong and little affected by the additional variable. This would suggest that the gain from education in the survival probability of female children is not just a proxy for a more general impact of socioeconomic status.

To some extent education might be hypothesized to be a measure of the resource position of the parent - indicating a level of ability of the parent to identify and make use of resources that improve the probability of the child surviving. The fact that education is a significant predictor for female and not for male mortality makes this interpretation somewhat awkward.

An alternative explanation may be that education reduces the influence of family size and sex preference. By this interpretation, parents who do not desire additional daughters, because they already have as many as they want, will, if they are educated, go to greater lengths to preserve the life of the child than they would if they had no education. To test this possibility we have run separate regressions for those without any education and those with either parent having at least some education. The basic coefficients reported in Table VIII remain unchanged, notably as they relate to the preference variable. When the reverse test was applied, that is, when we ran the regressions without the preference variables, the coefficients in general and those for education in particular remained largely unchanged. Thus a first examination would seem to suggest that preferences and educational status are largely independent.

Yet another explanation is that education may be a proxy for the age of the parents, since the younger women especially tend to be more educated. To examine this possibility we reran the post-neonatal female regression for 
two groups of women - younger and older. The education variable remained largely unchanged, as did most of the other coefficients except the preference variable which, while still statistically significant in each age group, was much stronger among the older women. This finding may reinforce the idea that the preference variable measures the discretionary component of mortality which we might expect to be stronger among older women nearer to their desired completed family size and composition.

A final possibility examined in this research is that educated parents may for various reasons be the recipients of more health-related services than those without education. For example, there is a statistically significant tendency for the more educated to use western medicine. Upon investigation there is some association between educational status and family planning, but not for either the receipt of $\mathrm{MCH}$ services or for the vaccinations of children. We examined the possibility that the mortality effect among females is the result of the interaction between family planning and education, but the effect is not discernable. This result may however relate to the skew in both the contraceptive use variable and in education.

To summarize our empirical findings then, education is not a statistically significant predictor for the mortality probability of males in either age group, but it is a significant and robust predictor of female mortality in the post-neonatal period.

Even though the effects are not statistically significant, there are some educational differentials for both males and females and for both age groups. Table IX summarizes our findings concerning the size of the differential for the different subgroups and its cumulative impact over the three years. The table is divided into two panels representing the male and female experience. Within each panel the first three columns summarize the probability of survival for the given age/cause as derived from the estimated equa-

TABLE IX

Estimated Sex-Specific Three-Year Survival Probabilities for Different Educational Groups

\begin{tabular}{|c|c|c|c|c|c|c|c|c|}
\hline \multirow{2}{*}{$\begin{array}{l}\text { Educational } \\
\text { Group }\end{array}$} & \multicolumn{4}{|l|}{ Male } & \multicolumn{4}{|l|}{ Female } \\
\hline & $\begin{array}{l}\text { Neonatal } \\
\text { Tetanus }\end{array}$ & Non-tetanus & $\begin{array}{l}\text { Post- } \\
\text { neonatal }\end{array}$ & Total & $\begin{array}{l}\text { Neonatal } \\
\text { Tetanus }\end{array}$ & Non-tetanus & $\begin{array}{l}\text { Post- } \\
\text { neonatal }\end{array}$ & Total \\
\hline $\begin{array}{l}\text { None } \\
\text { Father }\end{array}$ & 0.961 & 0.976 & 0.859 & 0.806 & 0.968 & 0.980 & 0.770 & 0.730 \\
\hline $\begin{array}{r}\text { only } \\
\text { Mother }\end{array}$ & 0.958 & 0.974 & 0.864 & 0.806 & 0.955 & 0.976 & 0.807 & 0.752 \\
\hline some & 0.968 & 0.989 & 0.911 & 0.872 & 0.979 & 0.989 & 0.915 & 0.886 \\
\hline Total & 0.943 & 0.968 & 0.852 & 0.778 & 0.953 & 0.972 & 0.799 & 0.740 \\
\hline
\end{tabular}


tions reported in Tables VI, VII, and VIII, when all explanatory variables are controlled. The last column represents the cumulative probability of survival for each education group, calculated as the product of the survival probabilities in the three categories. Thus male mortality is seen to be about one third lower among those families where the mother has some education than among the other two educational groups. Among the female births, the group with educated fathers only has a slightly lower level of mortality than those with none; but within the group where the mother has some education the mortality is less than half that of the other two groups.

The proportion of the sample households in which the mother has some education is very small. Within this group, however, there is a significant tendency for child mortality to be lower. Preliminary analysis suggests that while this effect may be partially attributable to the fact that women with education are associated with high-status households, some effect exists even when family background is controlled. The effect is particularly strong for female children and may be associated with an attempt on the part of the educated to invest some resources in their children independent of whether the child is desired and is of the preferred sex.

In closing we should emphasize the limitations of this research. The region from which the data are derived is not characterized by extensive education of either men or women. Even within this kind of social environment, our variables (e.g., cause of death or family size preferences) may be inadequately measured, and the model may in some sense be mis-specified, particularly with regard to the influence of preference variables. Despite these reservations, we believe our results show something of the complexity of socioeconomic determinants of mortality in general and of the important role of education in particular.

The empirical research in this paper provides ambiguous conclusions concerning the alternative explanations offered for the relationship between education and mortality offered at the beginning of the paper. On the one hand, the lack of statistically significant associations between education and neonatal mortality in the multivariate context suggests that the bivariate relationship may in large measure result because education acts as a proxy for the socioeconomic status of the parents. The same might be said for the male post-neonatal results. But the strong and robust relationship between education and female post-neonatal mortality is not so easily explained away and may represent a case where education basically transforms the individual. That the results should be particularly strong for educated mothers is especially suggestive. Further research might concentrate on the mechanisms by which this effect is transmitted. 


\section{Notes}

1 Deaths for which no cause was attributed were not included in tha analysis. In our earlier analysis we did not examine neonatal deaths by sex as the preliminary examination of mortality rates by cause did not indicate any major sex differences for that period (see Smucker et al., 1980).

2 See Simmons et al. (1980) for a detailed discussion of these results. In particular, it is important to recognize the bias in the coefficients of the preference variable arising from the way it is defined.

\section{References}

Cochrane, S.H. (1980). "The effects of education on health," World Bank Staff Working Paper No. 405, The World Bank, Washington.

Misra, B.D., Ashraf, A., Simmuns, R. and Simmons, G.B. (1982). Organization for Change: A Systems Analysis of Family Planning in Rural India. New Delhi: Radiant Publishers, and Ann Arbor, MI: South and Southeast Asian Studies Center.

Preston, S.H. (1980). "Causes and consequences of mortality declines in less developed countries during the twentieth century," in R.A. Easterlin, ed., Population and Economic Change in Developing Countries, Chicago: The University of Chicago Press, pp. 289-360.

Simmons, G.B., Smucker, C., Misra, B.D. and Majumdar, P. (1978). "Patterns and causes of infant mortality in rural Uttar Pradesh," Journal of Tropical Pediatrics and Environmental Child Health.

Simmons, G.B., Smucker, C., Bernstein, S. and Jensen, E. (1980). "Post-neonatal mortality in rural India: Implications of an economic model." Paper presented at the 1980 meeting of the American Public Health Association.

Smucker, C., Simmons, G.B., Bernstein, S. and Misra, B.D. (1980). "Neonatal mortality in South Asia: The special role of tetanus," Population Studies 34. 